\title{
Reducing of on polymerization shrinkage by application of UV curable dental restorative composites
}

\author{
Jolanta Świderska1, Zbigniew Czech $^{2 *}$, Waldemar Świderski ${ }^{1}$, Agnieszka Kowalczyk ${ }^{2}$ \\ ${ }^{1}$ Health Care Center, Bolestawa Śmiałego 28, 70-348 Szczecin, Poland \\ ${ }^{2}$ West Pomeranian University of Technology, Szczecin, Institute of Chemical Organic Technology, Pułaskiego 10, \\ 70-322 Szczecin, Poland \\ "Corresponding author: e-mail: psa_czech@wp.pl
}

\begin{abstract}
This manuscript describes dental compositions contain in-organic fillers, multifunctional methacrylates and photoinitiators. The main problem by application and UV curing process is the shrinkage of photoreactive dental materials during and after UV curing process. Total shrinkage of UV curable dental composites is a phenomenon of polymerization shrinkage, typical behavior for multifunctional methacrylates during polymerization process. The important factors by curing of dental composites are: kind and concentration of used methacrylates, their functionality, double bond concentration, kind and concentration of added photoinitiator and UV dose. They are investigated UV-curable dental compositions based on 2,2-bis-[4-(2-hydroxy-3-methacryxloyloxypropyl)phenyl]propane (Bis-GMA) and containing such multifunctional monomers as 1,3-butanediol dimethacrylate (1,3-BDDMA), diethylene glycol dimethacrylate (DEGDMA), tetraethylene glycol dimethacrylate (T3EGDMA), trimethylolpropane trimethacrylate (TMPTMA), polyethylene glycol 200 dimethacrylate (PEG200DA). Reduction of polymerization shrinkage of dental compositions is at the moment a major problem by dental technology.
\end{abstract}

Keywords: dental compositions, polymerization shrinkage, multifunctional methacrylates, UV-curing.

\section{INTRODUCTION}

In technology of dental materials the dental compositions can be divided into clinical and technical materials. Clinical materials are mainly used by the dentist technology in dental surgery, whereas technical materials are mostly applied by the dental technology by manufacturing of, for example, dentures. Various polymers have been widely used in dental materials for many years ${ }^{\mathbf{1}}$. Polymerization shrinkage is one of dental clinicians' main concerns when placing direct, posterior, resin-based composite restorations. Evolving improvements associated with resin-based composite materials, dental adhesives, filling techniques and light curing have improved their predictability, but shrinkage problems remain. The main motivation for the reduction of the shrinkage is too high shrinkage phenomenon by using in dental UV curable compositions of multifunctional methacrylates monomers ${ }^{2}$. Radical photopolymerization of dental compositions usually is performed by typical UV radiation or in UV visible area (UV-Vis) between 400 and $500 \mathrm{~nm}^{3}$. Polymerization shrinkage is influenced by clinical technique and manufacturing of the composite resin. This phenomenon is attributed to the formation of a three-dimensional, covalently crosslinked network during crosslinking, which reduces intermolecular distances between the monomers used to form the crosslinked network. Before cure, the molecules which comprise the resin are separated by their characteristic van der Waal's radii. Upon cure, these intermolecular distances are reduced due to the formation of covalent bonds between monomers which produce the desired highly crosslinked thermoset material ${ }^{4-9}$. This reduction of intermolecular distances creates internal stress throughout the thermoset network, which is manifested by reduced adhesion of the thermoset material to both the substrate and the object attached thereto. Shrinkage is a very important criterion in long term performance of adhesive and affects the adhesion properties inversely.
In order to control shrinkage, the UV dose and multifunctional methacrylates kind and concentration play very crucial role. In radiation curing free radicals are generated on the molecular chains which come closer to forming a crosslinked network. Because of coming closer of the molecular chains, shrinkage is occurred in the dental compositions which is detrimental for the performance of the polymer composition. There should be no shrinkage or least possible for good adhesion. Mutlifunctional methacrylates with the function as photoreactive crosslinkers are generally not incorporated in radiation curing but they have several benefits in improving the physical-mechanical properties of the adhesive. The shrinkage is dependent on nature and amount of crosslinker and also on radiation intensity.

It was well known that the shrinkage was the main drawback of free radical photo-polymerization. When the photo-polymerization shrinkage was constrained by adhesion to a substrate, in the case of dental compositions by adhesion to the tooth wall, shrinkage stress developed. Excessive stress resulted in defects such as curling and cracking which impeded the long-time application of UV-curable or UV-polymerizable materials. Besides, shrinkage also played the important and significant role to affect the marginal integrity of photo-curable system ${ }^{\mathbf{1 0}-\mathbf{1 8}}$.

\section{EXPERIMENTAL PART}

\section{Raw material}

The investigated multifunctional methacrylates: 2,2-bis-[4-(2-hydroxy-3-methacryxloyloxy-propyl)phenyl] propane (Bis-GMA), 1,3-butanediol dimethacrylate (1,3-BDDMA), diethylene glycol dimethacrylate (DEGDMA), tetraethylene glycol dimethacrylate (T3EGDMA), trimethylolpropane trimethacrylate (TMPTMA), and polyethylene glycol 200 dimethacrylate (PEG200DA) and bifunctional radical photoinitiator 2-hydroxy-1-\{4-[4-(2- 
Table 1. Multifunctional methacrylates and photoinitiator used in this work

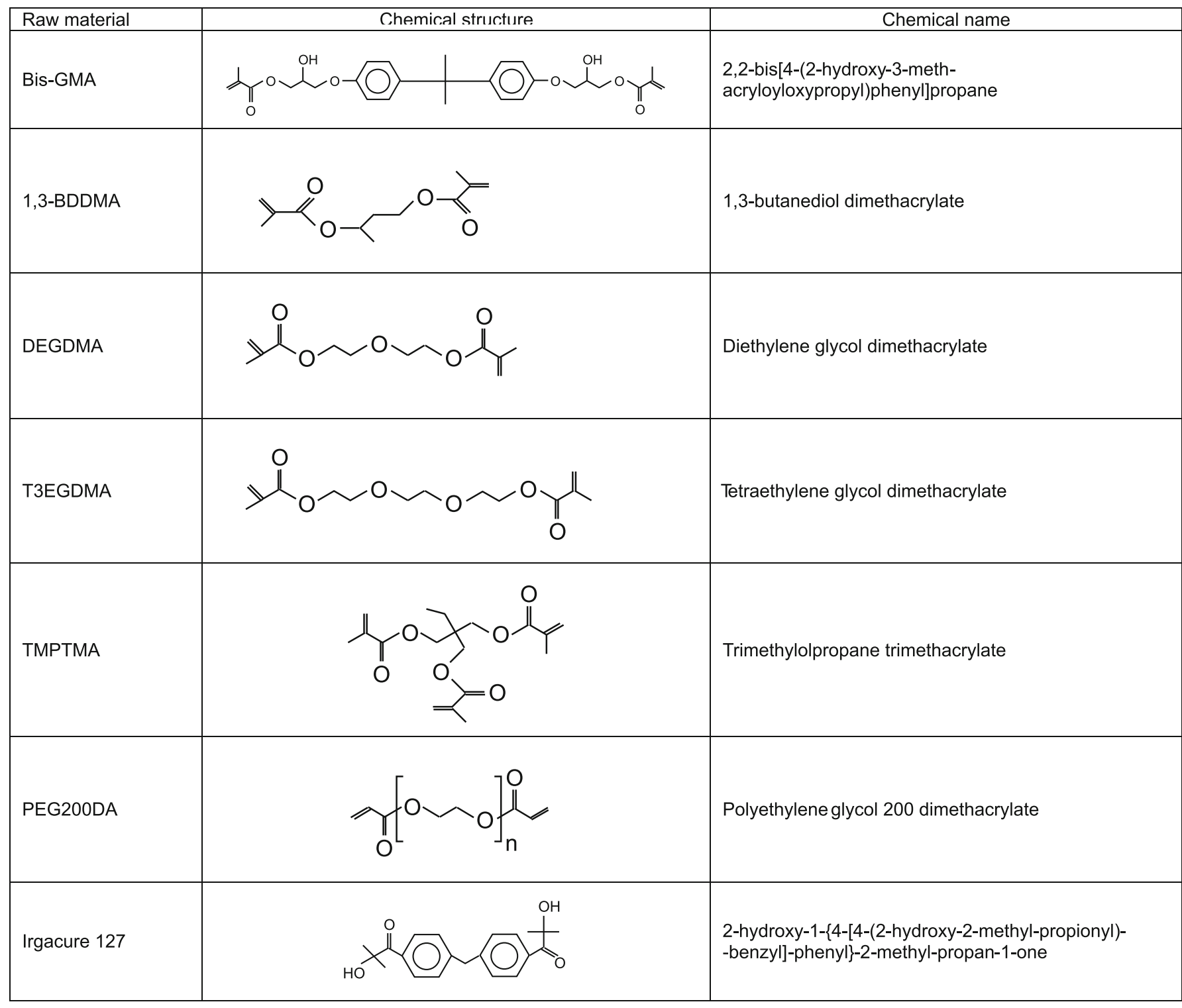

hydroxy-2-methyl-propionyl)-benzyl]-phenyl -2-methylpropan-1-one (Irgacure 127) are presented in Table 1.

All multifunctional methacrylates and photoinitiator Irgacure 184 are available from BASF (Germany), and hydroxyapatite is available from Continental Chemical (USA).

Hydroxylapatite in form of biocompatible white powder is the hydroxyl end member of the complex apatite group and crystallizers in the hexagonal crystal system. Thus, it is commonly used as filler for restorative dental compositions.

The investigated UV-curable dental composition containing following raw materials:

$\begin{array}{lr}\text { Bis-GMA: basic material } & 40 \mathrm{wt} . \% \\ \text { Multifunctional (meth)acrylate: } & 30 \mathrm{wt} . \% \\ \text { Hydroxyapatite } & 28 \mathrm{wt} . \% \\ \text { Irgacure 127 } & 2 \mathrm{wt} \%\end{array}$

\section{Measured of shrinkage}

The shrinkage studies of samples were conducted as per specification ${ }^{\mathbf{1 5}}$. A reflective laser scanning method based on the laser displacement sensor was used to directly measure shrinkage of UV-curing. The laser displacement sensor Keyence, LK-G10 (Japan) could detect the position of the upper surface of the sample (thickness of the sample). When photo-polymerization occurs, the thickness change of sample was recorded as the function of time. Percentage shrinkage $(\mathrm{S})$ is defined by the dimensional change according to the following equation:

$\mathrm{S}=\left(\mathrm{H}_{\mathrm{o}}-\mathrm{H}_{\mathrm{t}}\right) / \mathrm{H}_{\mathrm{o}}=\left(1-\mathrm{H}_{\mathrm{t}} / \mathrm{H}_{\mathrm{o}}\right) \times 100[\%]$

Where $\mathrm{H}_{\mathrm{o}}$ is the initial thickness and $\mathrm{H}_{\mathrm{t}}$ is the thickness at time t. The measured shrinkage is actually the linear shrinkage. However, as the planar dimensions are much greater than the thickness and constrain of planar shrinkage, the linear shrinkage appropriately equals to the volumetric shrinkage. The photopolymerization was conducted in the ambient condition at room temperature. The plane UV source (Emitting window: $25 \times 25 \mathrm{~mm}$ ) used was 395 nm LED RX Firefly SN 490454 from Phoseon Techology (USA). The radiometer from Hoenle UV Technology (Germany) was manipulated to detect the radiation intensity on the surface of samples, and UV intensity on the sample was adjusted to $5 \mathrm{~mW} / \mathrm{cm}^{2}$. 


\section{RESULTS AND DISCUSSION}

Variation of UV curing time, kind of multifunctional (meth)acrylates and functionality

To compare UV-behavior of multifunctional methacrylates with acrylates the photo-polymerization of dental composition containing multifunctional (meth)acrylates: tetraethylene glycol dimethacrylate (T3EGDMA), diethylene glycol dimethacrylate (DEGDMA), 1,3-butanediol dimethacrylate (1,3-BDDMA), trimethylolpropane trimethacrylate (TMPTMA) and polyethylene glycol 200 dimethacrylate (PEG200DMA), was examined. As shown in Figure 1, the commencement of irradiation is at $0 \mathrm{~s}$, at and before there no shrinkage.

The shrinkage of all tested monomers significantly increases during UV exposure. In the shrinkage profiles of all tested monomers, the obvious expansion after the very short induction time is observed (Fig. $1)$. This expansion is inducted by the accumulated curing, in this case polymerization, heat due to higher reactivity of acrylates in comparison to methacrylate. In Figure 1 also increases at very early stage of curing due to auto-acceleration effect. Because of the high reactivity, acrylate monomer PEG200DA shows much higher shrinkage than that of all tested methacrylates and needs less time to reach the maximum measurable shrinkage profile. Beyond this point, the shrinkage rate decreases due to significant reduction of monomers/ initiator/radicals (de-acceleration). Thus the shrinkage tends to reach equilibrium final shrinkage.

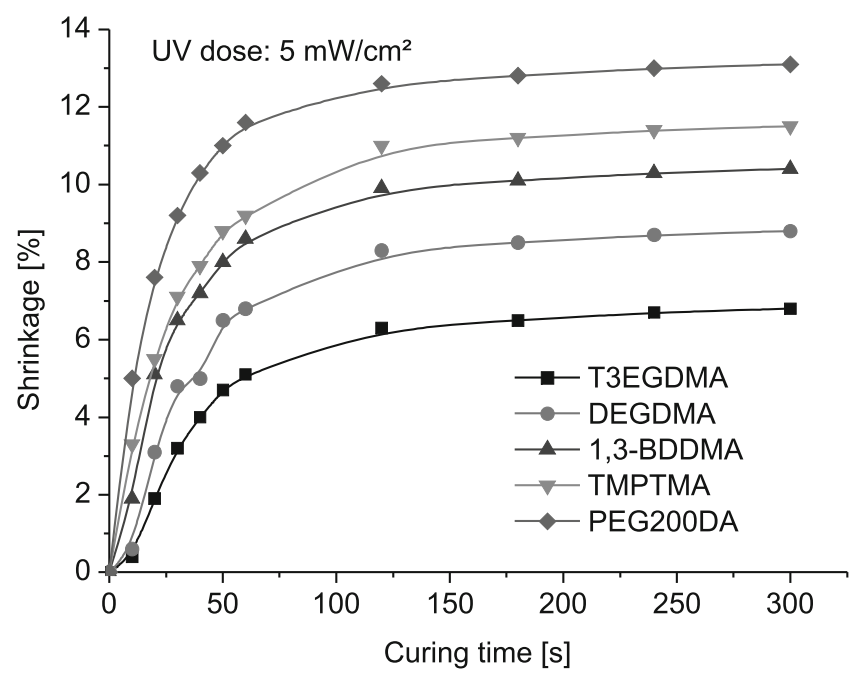

Figure 1. Shrinkage of dental filling containing investigated (meth)acrylates versus curing time

There is no doubt that the shrinkage depends on double bonds conversion because the shrinkage phenomenon is the consequence of polymerization process of investigated monomers what provides to curing of dental filling compositions. The double bond conversion of polymerized monomers can be assessing by comparison of shrinkage plateau of investigated monomers. After 240-300 s (4-5 min) shrinkage reaches maximal level and at this moment the conversion reaction of monomers double bonds is finished.

Table 3 presents molecular weight, density, functionality of investigated monomers, concentration of double bonds into their structure, and maximal shrinkage values after UV curing.

Changing the degree of ethoxylation (1,3-BDDMA, DEGDMA or T3EGDMA) is the convenient way to alter monomer chain lengths (the segment lengths between double bonds in monomers). It was used two methacrylates with different degree of ethoxylation, tri (DEGDMA) and four (T3EGDMA) mol ethoxy groups to evaluate the effect of monomer chain lengths on shrinkage. Figure 1 shows that when the degree of ethoxylation is raised, the shrinkage obviously decreases. Another dominant factor is the concentration of double bonds $\left(\mathrm{C}_{\mathrm{db}}\right)$, should be taken into consideration. The concentration of double bonds is defined as $\mathrm{C}_{\mathrm{db}}$ (Table 2). $\mathrm{C}_{\mathrm{db}}$ $[\mathrm{mol} / \mathrm{L}]=$ Functionality $\times$ Monomer density/Molecular weight, where $\mathrm{L}$ is monomer chain length. According to this equation, rising the degree of ethoxylation means reduction of the concentration of double bonds due to the significant increase of the molecular weight. In fact shrinkage depends on conversion and by full conversion on the concentration of double bonds. Because increase of monomer chain lengths has more significant effect on decreasing the concentration of double bonds than on increasing conversion, shrinkage is low even at high conversion. It was also observed that the maximum of shrinkage decrease from 8.8 to $6.8 \%$ with rising the degree of ethoxylation in Table 2. Thus, the monomer chain lengths effect on both the shrinkage is attributed to the change of the concentration of double bonds. Besides, the drop heat expansion in Figure 1 with decreasing the degree of ethoxylation is also due to the reduction of the concentration of double bonds. Thus, as shown in Table 3, the maximum of shrinkage level moved from the expansion stage to the shrinkage stage when the degree of ethoxylation was increased. The mobility of free radicals and monomeric and pendant double bonds rise due to the formation of less highly cross-link networks, and the segmental diffusivity of pendent double bonds rises due to the more flexible pendant double bonds. Thus, the propagation is less diffusion-controlled when the degree of ethoxylation is up.

The ethoxylation is attractive way to lower shrinkage because the concentration of double bonds significantly drops with increasing the molecular weight of ethoxylated multifunctional monomers. Likewise, other ways

Table 2. Monomers parameters and shrinkage of tested dental compositions

\begin{tabular}{|c|c|c|c|c|c|}
\hline Monomer & Functionality & Molecular weight [kg/kmol] & $\begin{array}{c}\text { Density at } 25^{\circ} \mathrm{C} \\
{\left[\mathrm{kg} / \mathrm{m}^{3}\right]}\end{array}$ & $\begin{array}{c}\text { Concentration } \\
\text { of double bonds } \\
\mathrm{C}_{\mathrm{db}}[\mathrm{mol} / \mathrm{L}]\end{array}$ & $\begin{array}{c}\text { Maximal shrinkage after UV curing } \\
{[\%]}\end{array}$ \\
\hline T3EGDMA & 2 & 286 & 1090 & 7.6 & 6.8 \\
\hline 1,3-BDDMA & 2 & 226 & 1010 & 8.9 & 10.4 \\
\hline TMPTMA & 3 & 338 & 1060 & 9.4 & 11.5 \\
\hline PEG200DA & 2 & 308 & 1110 & 7.2 & 13.1 \\
\hline
\end{tabular}




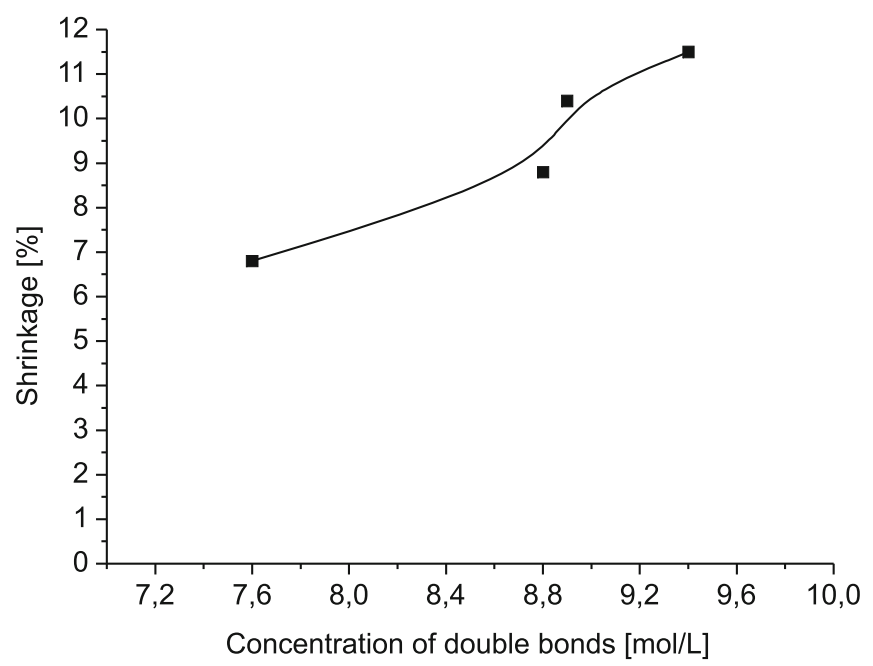

Figure 2. Shrinkage of dental composition containing multifunctional methacrylates versus concentration of double bonds in methacrylates

to increase the molecular weight may be promising to solve the shrinkage problem.

The influence of the concentration of double bonds in investigated methacrylate monomers shows Figure 2 (Table 2).

It is widely believed that reduction of functionality lowers the shrinkage. However, the functional effect on shrinkage is very complicated. Functionality obviously affects the conversion and the concentration of the double bonds. The concentration of the double bonds may not decrease with reducing functionality because changing the functionality is always accompanied by changing both the molecular weight and the density. In this work it were used the difunctionally T3EGDMA, DEGDMA and 1,3-BDDMA, and trifunctionally TMPTMA to evaluate the functional effect. As shown in Figure 1 and Table 3, the shrinkage level decreases with increase of monomers functionality, due to the formation of microgel in the early step. But the shrinkage don 't follow this trend. The trifunctionally methacrylate TMPTMA has the highest final shrinkage of $11.5 \%$ in comparison with other tested difunctionally methacrylates (Table 2).

\section{Influence of the UV dose on shrinkage}

Dependencies shown in Figure 1 point out that the UV dose during curing can influence shrinkage investigated dental filler compositions containing (meth)acrylate monomers. The UV-polymerization effect on shrinkage of tested (meth)acrylates, evaluated for UV doses between 10 and $50 \mathrm{~mW} / \mathrm{cm}^{2}$ and for $3 \mathrm{~min}$ UV-crosslinking time, is illustrated in Figures 3-7.

The results of tested dental compositions for shrinkage at different UV doses with variation of multifunctional monomers are given in Figures 3-7, which represents effect of UV polymerization dose in the range between 10 and $50 \mathrm{~mW} / \mathrm{cm}^{2}$. It was observed that with increasing of UV dose from 10 to $50 \mathrm{~mW} / \mathrm{cm}^{2}$ the shrinkage values during UV curing increase and remained constant level thereafter $120 \mathrm{~s}$, especially at higher UV doses up to $30-40 \mathrm{~mW} / \mathrm{cm}^{2}$. This indicates that UV dose of $50 \mathrm{~mW} /$ $\mathrm{cm}^{2}$ is sufficient enough to cure the investigated dental filling compositions. The maximum shrinkage was obse-

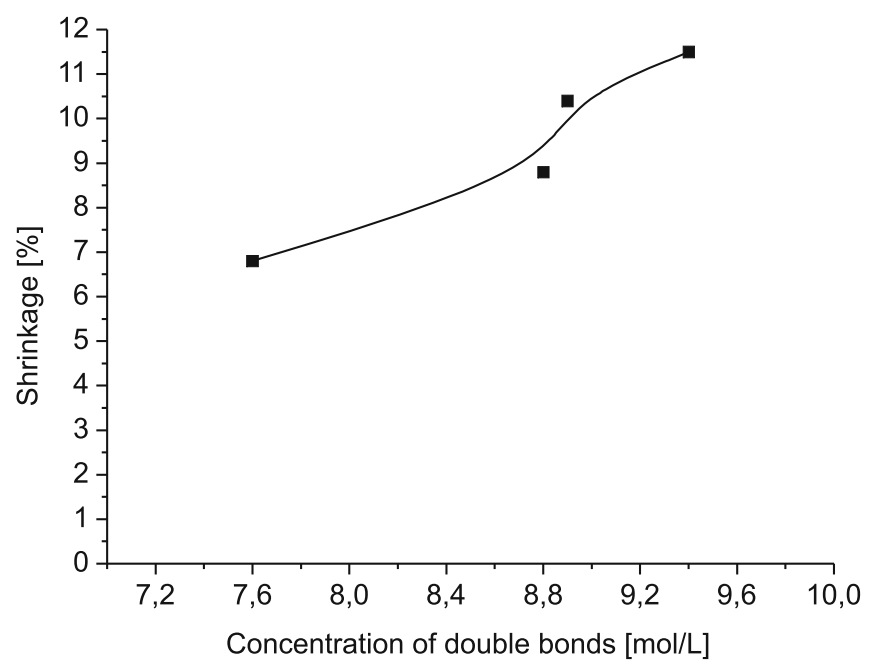

Figure 3. Shrinkage of dental filling containing monomer PEG200DA versus curing time and UV curing dose

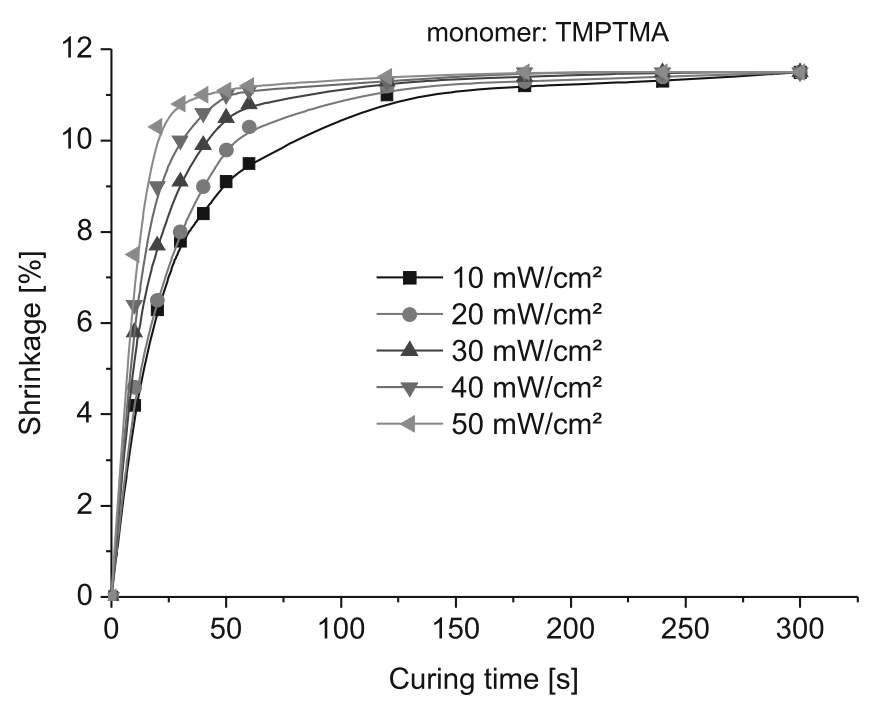

Figure 4. Shrinkage of dental filling containing monomer TMPTMA versus curing time and UV curing dose

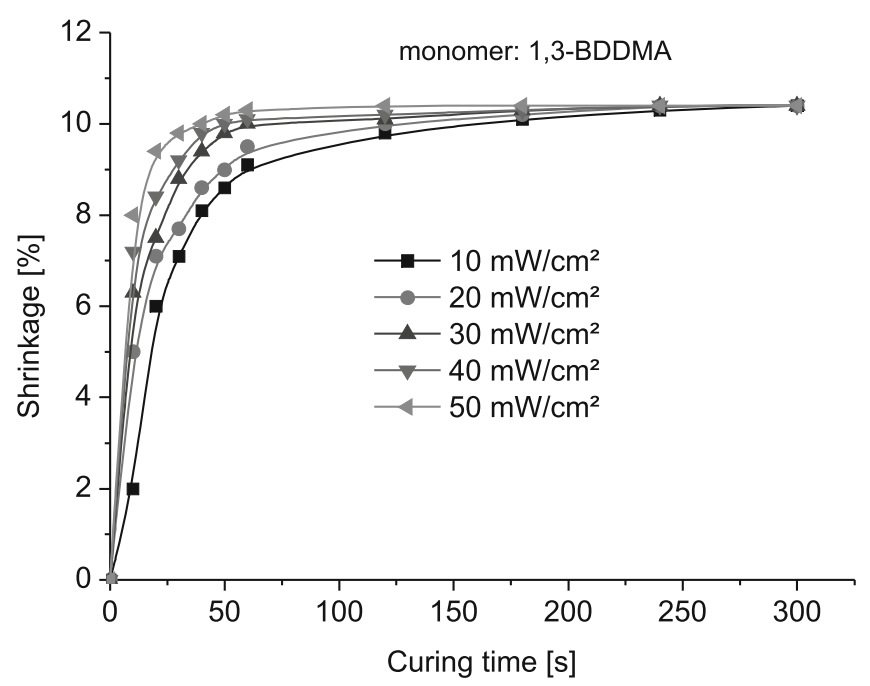

Figure 5. Shrinkage of dental filling containing monomer 1,3-BDDMA versus curing time and UV curing dose

rved for difuncional monomer polyethylene glycol 200 dimethacrylate (PEG200DMA).

\section{CONCLUSION}

The polymerization shrinkage of (meth)acrylate monomers mainly depended on the double bonds conver- 


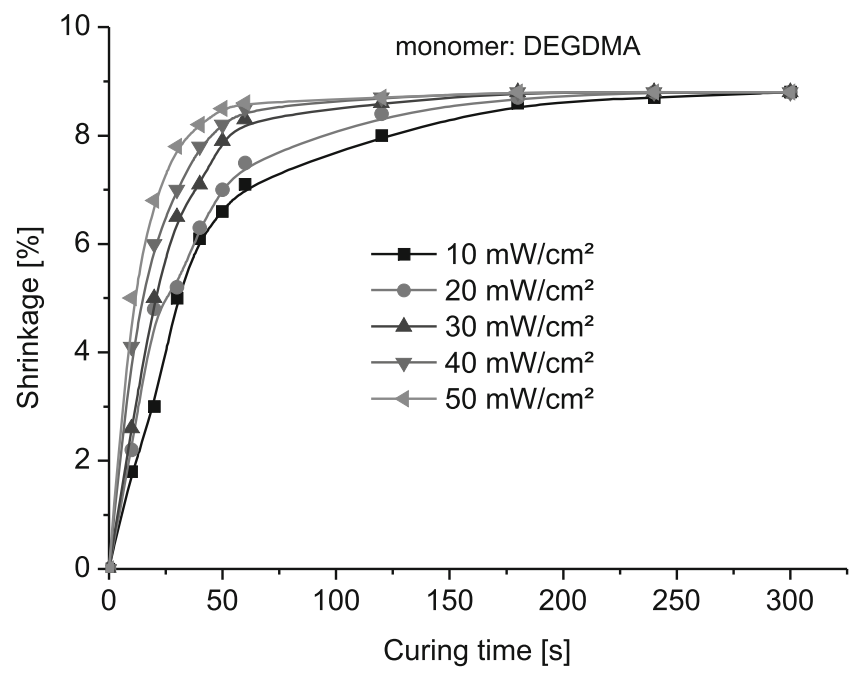

Figure 6. Shrinkage of dental filling containing monomer DEGDMA versus curing time and UV curing dose

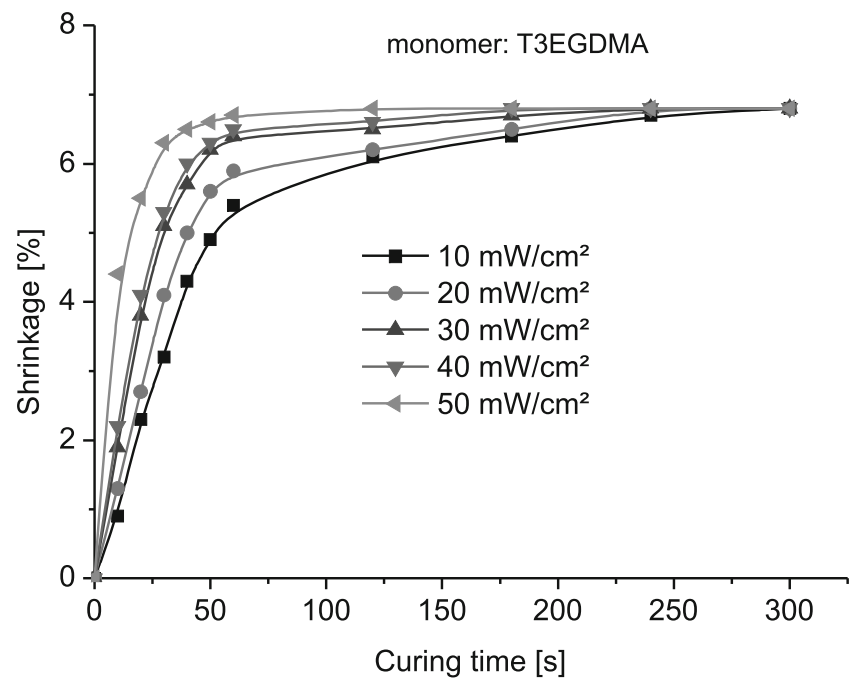

Figure 7. Shrinkage of dental filling containing monomer T3EGDMA versus curing time and UV curing dose

sion, concentration of double bonds, UV curing time and UV curing dose. Methacrylate monomers had low shrinkage than that of acrylate monomers because the low reactivity decreased the conversion as a function of curing time. Increase of chain length of monomers (rising the degree of ethoxylation) significantly lowered the shrinkage because the obvious rise of molecular weight decreased the concentration of double bonds. Reduction of functionality was not attractive way to lower the final shrinkage due to the combination effect of both the concentration of double bonds and conversion. The concentration of double bonds also played the important role in the shrinkage rate. When changing the degree of ethoxylation or monomer functionality, it was observed that shrinkage increased with the concentration of double bonds. Besides, heat expansion attributed to the curing could bring forward the maximum shrinkage rate from the shrinkage stage to the expansion stage. Thus, we believed that a promising way to decrease the shrinkage might be to increase the molecular weights of photoreactive monomers, if other properties such as viscosity and solubility meet application requirements.

\section{LITERATURE CITED}

1. Moszner, N. \& Hirt, T. (2012). New Polymer-Chemical Developments in Clinical Dental Polymer Materials: Enamel-Dentin Adhesives and Restorative Composites, J. Polym. Sci. Part A: Polym. Chem. 50, 4369-4402, DOI: 10.1002/pola.26260.

2. Feilzer, A.J. \& De Gee, A.J. (1987). Setting stress in composite resin in relation to configuration of the restoration, J. Dent. Res. 66, 1636-1639.

3. Moszner, N. \& Salz, U. (2007). Recent Developments of New Components for Dental Adhesives and Composites, Macromol. Mater. Eng. 292, 245-271, DOI: 10.1002/mame.200600414.

4. Liu, C.F., Collard, S.M. \& Armeniades, C.D. (1990). Constant-volume polymerization of composites by addition of ammoniamodified montmorillonite, Am. J. Dent. 3, 44-50.

5. Luo, J., Lannutti, J.J. \& Seghi, R.R. (1998). Effect of filler porosity on the abrasion resistance of nanoporous silica gel/polymer composites, Dent. Mater. 14, 29-36.

6. Czech, Z. (2001). Solvent-based pressure-sensitive adhesives for PVC surfaces: A special report, Adv. Polym. Techn. 20, 72-85.

7. Milker, R. \& Czech, Z. (2003). Removable and Repositionable Pressure-Sensitive Adhesive Products, STICK, 3rd European Congress of Adhesive and Sealant Raw Materials, Nürnberg, Germany 117-122.

8. Labella, R., Lambrechts, P., Van Meerbeek, B. \& Vanherle, G. (1999). Polymerization shrinkage and elasticity of flowable composites and filled adhesives. Dent. Mater. 15, 128-137.

9. Czech, Z. (2004). Studies of photoreactive acrylic adhesives with high shrinkage resistance, Pol. J. Chem. Technol. 4, 5-9.

10. Condon, J.R. \& Ferracane, J.L. (2000). Assessing the effect of composite formulation on polymerization stress, $J$. Am. Dent. Assoc. 131, 497-503.

11. Czech, Z., Kowalczyk, A., Kabatc J. \& Świderska, J. (2012). Solvent-based of acrylic pressure-sensitive adhesive of low shrinkage, Eur. Polym. J. 48, 1446-1454.

12. Kemp-Scholte, C.M. \& Davidson, C.L. (1990). Complete marginal seal of Class $\mathrm{V}$ resin composite restorations effected by increasing flexibility, J. Dent. Res. 69, 1240-1243.

13. Czech, Z., Butwin, A., Kabatc, J. \& Świderska, J. (2012). UV-crosslinkable acrylic pressure-sensitive adhesives for industrial application, Polym. Bull. 69, 71-80.

14. Davidson, C.L. \& De Gee, A.J. (1984). The competition between the composite-dentin bond strength and polymerization contraction stress, J. Dent. Res. 63, 1396-1399.

15. Jian, Y., He, Y. \& Jiang, T. (2012). Polymerization shrinkage of (meth)acrylate determined by reflective laser beam scanning, J. Polym. Sci. Part B: Polym. Phys. 50, 923-928.

16. Singh, A.K., Mehra, D.S. \& Niyogi, U.K. (2011). Polyurethane based pressure-sensitive adhesives (PSAs) using electron beam irradiation for medical application, J. Polym. Mater. 28, 525-542.

17. Jin, X., Bai, Y., Shao, L., Yang, B. \& Tang, Y. (2009). Properties of solvent-borne acrylic pressure-sensitive adhesives synthesized by a simple approach, Exp. Pol. Let. 3, 814-820.

18. Czech, Z., Wilpiszewska, K., Tyliszczak, B., Jiang, X., Bai, Y. \& Shao, L. (2013), Biodegradable self-adhesive tapes with starch carrier, Int. J. Adhes Adhes 44, 195-199. 